Revista de
Economild
Contemporâned

\title{
DINÂMICA ECONÔMICA E CICLOS DE NEGÓCIOS NA ECONOMIA BRASILEIRA: EVIDÊNCIAS PARA O PERÍODO PÓS-REAL
}

\author{
Reisoli Bender Filho ${ }^{a}$ \\ aProfessor Adjunto do Departamento de Ciências Administrativas e do Programa de \\ Pós-Graduação em Administração da Universidade Federal de Santa Maria (UFSM).
}

Artigo recebido em 19/01/2016 e aprovado em 03/05/2017.

RESUMO: O exame dos ciclos de negócios da economia brasileira no pós-Real faz-se tema pertinente quando considerado que esse período indica a existência de choques de oferta e de demanda. Buscando testar essa evidência, fez-se uso de dois modelos: o Money-in-the-Utility function (MIU) e o Cash-in-Advanced (CIA). As economias artificiais simuladas - padrão e monetária - mostraram maior aderência aos fatos estilizados quando considerado o modelo com rigidez dos preços e salários, embora o comportamento volátil das variáveis nominais não tenha sido reproduzido completamente em ambas às economias artificiais. Todavia, os efeitos de choques monetários não podem ser subestimados, haja vista que possibilitaram evidenciar comportamentos característicos de economias com certo grau de instabilidade.

PALAVRAS-CHAVE: ciclos de negócios; Money-in-the-Utility function; Cash-in-Advanced; economia brasileira.

CLASSIFICAÇÃO JEL: E32, C61, C32.

Correspondência para: Reisoli Bender Filho.

Contato: reisolibender@yahoo.com.br. 


\title{
ECONOMIC DYNAMIC ANDBUSINESS CYCLES IN THE BRAZILIAN ECONOMY: EVIDENCE FOR THE POST-REAL PERIOD
}

\begin{abstract}
The exam of Brazilian Economy's cyclic in the post-real period is considered a relevant theme when considered that the this it indicates the simultaneous existence of supply and demand shocks. Tring to show it, the models Money-in-theUtility function (MIU) and Cash-in-Advanced (CIA) have been used. Although the artificial economies simulated -pattern and monetary- have shown higher adequacy to stylized facts when the rigidities of prices and salaries are considered, the volatile behavior of nominal variables had not been completely reproduced in both artificial economy. The effect of monetary shocks can't be under estimated, because they showed characteristic behavior of economies with a certain level of instability.
\end{abstract}

KEYWORDS: business cycles; Money-in-the-Utility function; Cash-in-Advanced; Brazilian economy. 


\section{INTRODUÇÃO}

Os modelos de ciclos reais de negócios, ao considerar que as flutuações da atividade econômica são respostas eficientes dos mercados aos choques de oferta, consideram que as variáveis monetárias não exercem efeito sobre o produto agregado, assim como nas demais variáveis reais. Esta pressuposição está pautada na condição de que os preços e salários são perfeitamente flexíveis, permitindo à economia ajustar-se instantaneamente, de forma a retornar ao equilíbrio de longo prazo.

No entanto, esta pressuposição de neutralidade da moeda tem sido questionada, uma vez que os fatos econômicos têm evidenciado que a instabilidade monetária está entre as causas mais recorrentes das crises ocorridas nas modernas economias industriais, tanto desenvolvidas quanto em desenvolvimento. Tal evidência baseia-se no fato de que os ciclos da moeda antecedem os ciclos da atividade econômica, o que indicaria que mudanças na oferta de moeda seriam não totalmente neutras, provocando com isso o ajuste incompleto dos preços e salários, conforme discutido em Friedman e Schwartz (1963) e também em Christiano, Eichenbaum e Evans (2005).

Sobre esse aspecto, Cooley e Hansen (1995) discutem que o problema está em mostrar como impulsos monetários são causas relevantes das flutuações dos ciclos de negócios em economias em que se assume que os agentes comportam-se racionalmente e que as flutuações cíclicas são originadas por choques tecnológicos. Sustentando tal proposição, duas abordagens teóricas formalizaram modelos de economias monetárias com a introdução da moeda na estrutura dos modelos neoclássicos de crescimento: (1) saldos monetários reais podem ser incluídos diretamente como argumento na função utilidade dos agentes, proposta formulada por Sidrausky (1967), e (2) manutenção de moeda para financiar compras de bens de consumo ou algum subconjunto destes bens, proposta baseada na abordagem novo-Keynesiana (ver FISCHER, 1977; TRIGARI, 2004; e WALSH, 2005).

Esta hipótese encontra paralelo no cenário macroeconômico brasileiro das duas últimas décadas, iniciado com a implementação do Plano Real, em 1994, cujos resultados econômicos, em grande medida, tem sido consistentes com choques de demanda (ver KANCZUK, 2004), bem como resultado da política econômica expansionista (ver DELFIN NETO, 2011). Neste ínterim, as políticas de demanda, baseadas na política monetária de fixação e ajuste sistemático da taxa básica de juros têm sido utilizadas para controlar o comportamento inflacionário. Sobre este aspecto, Carvalho (2014) discute que as ameaças de uma instabilidade inflacionária são percebidas pelos agentes como um sinal de mudanças nas políticas de demanda, sendo também tais choques instrumentos de controle à política econômica expansionista. 
Pautado nesta discussão, o texto centra-se em explorar os efeitos quantitativos de choques monetários sobre as flutuações cíclicas da economia brasileira entre 1994 e 2013. Além disso, objetiva debater dois aspectos complementares: (1) efeitos diferenciados dos choques tecnológicos e monetários e; (2) a adequação de modelos dinâmicos à economia brasileira no período pós-Real. Para avaliar tais efeitos, fez-se uso das duas abordagens teóricas, a que incorpora a moeda na função utilidade dos agentes, o modelo Money-in-the-Utility function (MIU), e a que considera a rigidez nominal dos preços, o modelo Cash-in-Advance (CIA).

Nos trabalhos sobre ciclos de negócios tem predominado a abordagem da Real Business Cycle Theory (RBC), conforme encontrado inicialmente em Kydland e Prescott (1982), Long e Plosser (1983) e Hansen (1985) e mais recentemente em Francis e Ramey (2002), Rebelo (2005) e Kiyotaki (2011), em que as flutuações econômicas são originadas por choques de produtividade. Diferentemente, este introduziu conjuntamente choques tecnológicos e monetários como fonte de mudanças no comportamento dinâmico da economia brasileira em linha com Kanczuk (2004) que ressalta que os dados reais do período pós-estabilização parecem ser consequência da existência simultânea de choques de oferta e de demanda. Logo, na estrutura básica dos modelos estocásticos (Dynamic Sthocastic General Equilibrium - DSGE) foram incorporadas características de ambos os distúrbios.

Estudos com esse enfoque encontram-se em número reduzido e são recentes na economia brasileira, ao passo que há ainda uma lacuna no entendimento de como choques nominais impactam o ciclo econômico, sobremaneira nas últimas duas décadas, quando a política econômica implementada, pautada na manutenção da estabilidade de preços, interrompeu o processo de cronicidade inflacionária, aspecto que necessita ser discutido com maior grau de detalhamento. Entre os estudos, mencionam-se os de Kanczuk (2004), Sin e Gaglianone (2006), Silveira (2008), Souza-Sobrinho (2010), Cavalcanti e Veredas (2011), Bender Filho et al. (2012), Vasconcelos e Divino (2012), e Teles e Mendonça (2013).

Além dessa introdução, o trabalho está estruturado em mais quatro seções. As duas seguintes apresentam a fundamentação teórica e os aspectos metodológicos dos modelos Money-in-the-Utility function e Cash-in-Advanced. A quarta seção inicia com a apresentação dos parâmetros e a características da economia real e finaliza com a discussão dos resultados e o ajustamento das economias monetárias. A quinta seção conclui, sendo sumarizadas as principais considerações acerca da temática e dos resultados encontrados. 


\section{MODELOS MONEY-IN-THE-UTILITY (MIU) E CASH-IN-ADVANCED (CIA)}

\subsection{O MODELO MIU: FUNÇÕES DE PREFERÊNCIA E TECNOLOGIA E PROBLEMA DO CONSUMIDOR}

As propriedades do modelo Money-in-the-Utility function, proposto por Sidrausky (1967), consideram que a utilidade depende unicamente das decisões de consumo e da manutenção de moeda. Todavia, para estudar as flutuações dos ciclos de negócios, deve-se considerar que a utilidade também depende das decisões relacionadas à oferta de trabalho (WALSH, 2003).

Especificamente, a função utilidade determina um continuum de famílias homogêneas vivendo infinitamente num intervalo [0,1] e assume a forma funcional CES (Constant Elasticity Substitution), que pode ser escrita como:

$$
u\left(c_{t}, m_{t}, l_{t}\right)=\frac{C_{t}^{1-\Phi}}{1-\Phi}+\Psi \frac{\left(1-h_{t}\right)^{1-\eta}}{1-\eta}
$$

em que $C$ é um bem de consumo composto, $\Phi$ é o inverso da elasticidade de substituição intertemporal no consumo (coeficiente de aversão relativa ao risco), $\eta$ é o inverso da elasticidade da oferta de trabalho e $\Psi$ é um parâmetro positivo associado a contingência do lazer, com os parâmetros seguindo as seguintes condições:

$$
\eta, \Phi, \Psi>0 \text { e } \eta, \Phi \neq 1
$$

À função de produção segue-se a especificação padrão dos modelos neoclássicos de equilíbrio geral dinâmico e estocástico, assumindo que a economia produz um único produto, a partir dos insumos capital e trabalho, de acordo com a função produção Cobb-Douglas, com retornos constantes à escala, assim definida:

$$
y_{t}=f\left(k_{t}, h_{t},{ }_{t}\right)=z_{t} k_{t} \alpha{ }_{t}{ }_{t}-\alpha, 0<\alpha<1,
$$

sendo $k$ o estoque de capital per capita, $h$ a quantidade total de horas trabalhadas, $\alpha$ a parcela do capital no produto (na renda) nacional, $(1-\alpha)$ a parcela do trabalho na renda nacional e $z$ o distúrbio exógeno que segue um processo de tecnologia estocástica. Assume-se que a função de produção satisfaz as condições de Inada:

$$
f_{k}>0 \text { e } f_{h}>0 \mathrm{com} f_{k k}<0, f_{h h}<0 \text { e } f_{k h}>0 .
$$


Para tanto, a tecnologia está sujeita à lei de movimento do capital determinada por $k_{t+1}=(1-\delta) k_{t}+i_{t}$, e sujeita a restrição de possibilidade $f\left(k_{t}, h_{t}, z_{t}\right) \geq c_{t}+i_{t}$. Sendo $\delta$ a taxa de depreciação, que se encontra no intervalo entre 0 e 1 , e $i$ o investimento agregado.

Definidas as formas funcionais, a etapa seguinte consistiu em: (i) definir o problema de decisão das famílias e (ii) obter as condições de primeira ordem às variáveis endógenas. A partir de tais condições, o agente representativo tem como objetivo maximizar a utilidade descontada condicionada às restrições, como apresentado em (3):

$$
\max E_{0}\left[\sum_{t=0}^{\infty} \beta^{t}\left(\frac{C_{t}^{1-\Phi}}{1-\Phi}+\Psi \frac{l^{1-\eta}}{1-\eta}\right)\right], \quad 0<\beta<1
$$

sujeito a restrição orçamentária determinada por:

$$
\begin{aligned}
& f\left(k_{t}, h_{t}, z_{t}\right)+(1-\delta) k_{t-1}+\omega_{t} \geq c_{t}+k_{t}+d_{t}+m_{t} \\
& \omega_{t}=\tau_{t}+\left[\left(1+j_{t-1}\right) /\left(1+\pi_{t}\right)\right] d_{t-1}+m_{t-1} / 1+\pi_{t}
\end{aligned}
$$

sendo $E$ o operador de expectativa, $\beta$ a taxa de desconto intertemporal, com $0<\beta<1$, $\omega_{t}$ a riqueza real financeira do agente, $\tau_{t}$ a transferência real recebida do governo, $d_{t}$ estoque de títulos livres de risco, $j_{t}$ a taxa nominal de juros e $\pi_{t}$ a taxa de inflação.

Sendo este um problema de otimização dinâmica, pode-se escrever o modelo como uma equação de Bellman, de forma que a função $(V)$ representa o valor presente máximo da utilidade que o agente representativo das famílias pode alcançar:

$$
\begin{gathered}
V\left(\omega_{t}, k_{t-1}\right)=\max _{c_{t}, m_{t}, n_{t}, b_{t}, k_{t}} \\
u\left(c_{t}, m_{t}, 1-h_{t}\right)+\beta E_{t} V\left(\omega_{t+1}, k_{t}\right)
\end{gathered}
$$

com a maximização sujeita a restrição orçamentária avaliada em $t+1$; sendo $\omega_{t}, k_{t-1} \mathrm{e}$ $z_{t}$, as variáveis de estado e $c_{t}, k_{t}, h_{t}, d_{t}$ e $m_{t}$ as variáveis de controle. O tratamento de $\omega_{t}$ como variável de estado determina que a taxa de crescimento monetário é conhecida no tempo em que as famílias tomam suas decisões sobre consumo, estoque de capital, horas trabalhadas, títulos e saldos monetários reais. Da mesma forma, considera-se que o distúrbio da produtividade, $z_{t}$ é conhecido no início do período $t$. 


\subsubsection{ESTADO ESTACIONÁRIO}

Os valores do estado estacionário são expressos em termos dos parâmetros básicos do modelo - produto, consumo, estoque de capital e horas trabalhadas -, representadas respectivamente por $y^{S S}, c^{S S}, k^{S S}$ e $h^{S S}$. Inicialmente, a equação de Euler no estado estacionário à taxa de desconto intertemporal é determinada pelo inverso da taxa real de retorno sobre o capital (ou pelo inverso da taxa real de juros), como segue:

$$
\beta=1 / R^{S S}, \operatorname{com} R^{S S}=\alpha(y / k)+1-\delta
$$

em que $R^{S S}$ é a taxa real de juros de equilíbrio.

Considerando a taxa de desconto intertemporal definida em (7), a razão produto-capital no estado estacionário é dada pela seguinte expressão:

$$
\left(y^{S S} / k S S\right)=\frac{1}{\alpha}\left(\frac{1}{\beta}-1+\delta\right)
$$

Da função de produção apresentada em (2), tem-se $\left(y^{S S / k}\right)=\left(h^{S S / k}{ }^{S S}\right)^{1-\alpha}$ que determina $\left(y^{S S / k} S S\right)=z_{t}\left(h^{S S} / k^{S S}\right)^{1-\alpha}$, considerando que no equilíbrio de longo prazo o choque tecnológico é conhecido, tal que $z_{t}=1$, obtém-se:

$$
\left(h^{S S} / k^{S S}\right)=\left(y^{S S} / k^{S S}\right) \overline{1-\alpha}=\left[\frac{1}{\alpha}\left(\frac{1}{\beta}-1+\delta\right)\right]^{\frac{1}{1-\alpha}} .
$$

Da restrição orçamentária agregada apresentada em (4):

$$
\left(c^{S S} / k^{S S}\right)=\left(y^{S S} / k^{S S}\right)-\delta=\frac{1}{\alpha}\left(\frac{1-\beta}{\beta}\right)+\left(\frac{1-\alpha}{\alpha}\right) \delta \text {, sendo }\left(1+j^{S S}\right)=R^{S S}\left(1+\pi^{S S}\right)
$$

Os valores do estado estacionário revelam as propriedades do modelo MIU e como variações na taxa de inflação no equilíbrio afetam o produto e o consumo agregado. A partir da função avaliada em (6), no estado estacionário, geram-se as seguintes expressões:

$$
\left(m^{S S} / c^{S S}\right)=\left(\frac{a}{1-a}\right)^{-\frac{1}{b}}\left(\frac{\Theta-\beta}{\Theta}\right)^{-\frac{1}{b}},
$$




$$
\begin{aligned}
& m^{S S} / k^{S S}=\left(\frac{a}{1-a}\right)^{-\frac{1}{b}}\left(\frac{\Theta-\beta}{\Theta}\right)^{-\frac{1}{b}}\left(c^{S S / k} S S\right) \\
& h^{S S} / k^{S S}=\left(y^{S S} / k^{S S}\right)^{\frac{1}{1-\alpha}} .
\end{aligned}
$$

Exceto as expressões do saldo monetário real relativo ao consumo e ao estoque de capital, as demais $(7,8,10$ e 13) são independentes da taxa de crescimento da oferta nominal de moeda no estado estacionário. Ressalta-se que os níveis do estoque de capital, do produto e do consumo no estado estacionário dependerão da taxa de crescimento monetário. Nesta situação, a taxa de inflação induz mudanças em $h$ no estado estacionário, enquanto que o produto, o consumo e o estoque de capital serão afetados proporcionalmente. Logo, $h^{\text {ss }}$ pode ser obtido a partir das formas funcionais da função utilidade e de produção, tal que:

$$
\frac{\left(h^{S S}\right)^{\Phi}}{\left(1-h^{S S}\right)^{\eta}}=H\left[1+\left(\frac{a}{1-a}\right)^{-\frac{1}{b}}\left(\frac{\Theta-\beta}{\Theta}\right)^{\frac{b-1}{b}}\right]^{\frac{b-\Phi}{1-b}}
$$

Essa expressão em (14) é independente da taxa de crescimento da oferta nominal de moeda no estado estacionário, enquanto que o lado esquerdo é crescente em $h^{S S}$. Logo, o efeito de um maior crescimento monetário, $\Theta$, sobre o lado direito depende do sinal de $\xi=(b-\Phi)$. Sendo positivo $(b-\Phi>0)$, taxas de inflação maiores reduzem a utilidade marginal do consumo, aumentando a demanda por lazer e reduzindo a oferta de trabalho. Como consequência, o estado estacionário do produto tenderá a cair. Nesta situação, consumo e moeda são complementares.

Sendo negativo $(b-\Phi<0)$, taxas de inflação elevadas conduzem ao aumento da oferta de trabalho, pelo aumento da utilidade marginal do consumo, o que tenderá a elevar o nível do produto agregado no estado estacionário. E, se $b-\Phi=0$, nem a utilidade marginal do consumo nem a utilidade marginal do lazer dependem do nível do saldo monetário real, de forma que não se rejeita a hipótese da neutralidade da moeda. Situação em que as motivações e as decisões dos agentes econômicos não seriam influenciadas por mudanças monetárias. 


\subsection{O MODELO CIA: FUNÇÕES DE PREFERÊNCIA E TECNOLOGIA E PROBLEMA DO CONSUMIDOR}

A função de preferência da família representativa no modelo CIA determina um continuum de famílias homogêneas vivendo infinitamente num intervalo [0,1], da mesma forma que no modelo MIU. A tecnologia é dada por uma função Cobb-Douglas, com retornos constantes à escala, expressa em termos per capita, assim definida:

$$
y_{t}=z_{t} k_{t^{\alpha}} h_{t^{1-\alpha}}, 0<\alpha<1,
$$

em que $k$ define o estoque de capital per capita no período $t-1, h$ a quantidade total de horas trabalhadas, $\alpha$ a parcela do capital no produto (na renda) nacional, $(1-\alpha)$ a parcela do trabalho na renda nacional e $Z$ é um distúrbio exógeno que segue um processo de tecnologia estocástica. De forma semelhante, a função de produção satisfaz as condições de Inada.

Nesta especificação, a porção do produto que não é consumida é investida em capital físico. Logo, o investimento no período $t$ produz capital produtivo em $t+1$, situação em que a função de produção está sujeita à lei de movimento do capital determinada por $k_{t+1}=(1-\delta) k_{t}+i_{t}$, tendo como restrição de possibilidade $f\left(k_{t}, h_{t}, z_{t}\right) \geq c_{t}+i_{t}$.

Apresentadas as formas funcionais para as funções de preferência e tecnologia, $o$ problema de decisão das famílias consiste em maximizar a função utilidade descontada, considerando a incerteza e as restrições, conforme se encontra em (16):

$$
\max E_{0} \sum_{i=0}^{\infty} \beta^{i} u\left(c_{t+i}, 1-n_{t+i}\right)=E_{0} \sum_{i=0}^{\infty} \beta^{i}\left[\frac{c_{t+i}^{1-\Phi}}{1-\Phi}+\Psi \frac{\left(1-n_{t+i}\right)^{1-\eta}}{1-\eta}\right], 0<\beta<1
$$

em que $c_{t}$ define o consumo real, $n_{t}$ a oferta de trabalho, expressa como uma fração do tempo total disponível e $1-n_{t}$, o tempo destinado ao lazer; os parâmetros $\Phi, \Psi$ e $\eta$ são números positivos.

As famílias ofertam trabalho e capital às firmas, fatores que são utilizados para produzir bens; em termos nominais, possuem saldos monetários mantidos do período anterior $M_{t-1}$ e recebem transferências do governo (pagamentos nominais) iguais a $T_{t}$. Quanto considerada a formulação estocástica, a variável $\theta$ define a taxa de crescimento da oferta monetária, sendo consistente $\operatorname{com}\left(M_{t}=(1+\theta) M_{t-1}\right)$. Destaca-se que no início do período, a taxa de crescimento da oferta de moeda é conhecida por todos os agentes.

No modelo Cash-in-Advanced, as restrições são impostas somente sobre as compras de bens de consumo, conforme segue: 


$$
P_{t} c_{t} \leq M_{t-1}+T_{t}
$$

em que $P_{t}$ é o nível de preço no tempo $t$, período em que as transferências recebidas estão disponíveis para serem gastas também em $t$.

$$
c_{t} \leq m_{t-1} / \Pi_{t}+\tau_{t} \text {, sendo } \Pi_{t}=P_{t} / P_{t-1}=1+\pi_{t}
$$

em que $\tau_{t}$ são as transferências e $\pi_{t}$ a taxa de inflação.

Complementarmente, o fluxo de restrição orçamentária das famílias é determinado por:

$$
y_{t}+(1-\delta) k_{t-1}+\left(\frac{1+i_{t-1}}{1+\pi_{t}}\right) b_{t-1}+\frac{m_{t-1}}{\Pi_{t}}+\tau_{t} \geq c_{t}+k_{t}+b_{t}+m_{t},
$$

Sendo este um problema de otimização dinâmica, o problema de decisão dos indivíduos é caracterizado como uma função valor:

$$
V\left(k_{t-1}, b_{t-1}, m_{t-1}\right)=\frac{\max }{c_{t}, n_{t}, k_{t}, b_{t}, m_{t}}\left[\frac{c_{t}^{1-\Phi}}{1-\Phi}+\Psi \frac{\left(1-n_{t}\right)^{1-\eta}}{1-\eta}+\beta E_{t} V\left(k_{t}, b_{t}, m_{t}\right)\right]
$$

sendo a maximização com respeito a $\left(c_{t}, n_{t}, k_{t}, b_{t}\right.$ e $\left.m_{t}\right)$ e sujeita as restrições (19) e (18).

\subsubsection{ESTADO ESTACIONÁRIO}

O estado estacionário de $R^{S S}, y^{S S} / k^{S S}, c^{S S} / k^{S S}$ no modelo CIA é análogo àquele encontrado no modelo MIU (correspondente às expressões 7, 8 e 10, respectivamente), a exceção está na expressão para os saldos monetários reais. No estado estacionário, a restrição do modelo CIA é obrigatória enquanto que ataxa de juro nominal é positiva, diferentemente do modelo MIU. Assim, $c^{S S}=\tau^{S S}+m^{S S} /\left(1+\pi^{S S}\right)$ e, sendo que no estado estacionário $m$ é constante, tem-se que $\tau^{S S}+m^{S S} /\left(1+\pi^{S S}\right)=m^{S S}$. Deste modo, $m^{S S}=$ $c^{S S}$ ou $m^{S S} / k^{S S}=c^{S S} / k^{S S}$. Logo, observa-se que nenhuma das expressões para o estado estacionário depende da taxa de crescimento da oferta nominal de moeda.

Já o estado estacionário da oferta de trabalho dependerá da taxa de crescimento monetário e, por conseguinte, da taxa de inflação:

$$
\left(1-n^{S S}\right)^{-\eta}=\frac{(1-\alpha)}{\Psi}\left(\frac{\beta}{\Theta}\right)\left(\frac{y^{S S}}{k^{S S}}\right)^{\frac{\Phi-\alpha}{1-\alpha}}\left(\frac{c^{S S}}{k^{S S}}\right)^{-\Phi}, \operatorname{com} \Theta=1-\theta=\Pi^{S S},
$$


Sendo o lado esquerdo crescente em $n^{S S}$, um aumento em $\Theta$ implica em uma elevação da taxa de inflação e em um menor nível da oferta de trabalho. Desta forma, a elasticidade da oferta de trabalho com respeito à taxa de crescimento da oferta de moeda é negativa, diferentemente do modelo MIU onde o maior crescimento monetário determina um efeito ambíguo na oferta de trabalho.

\subsection{CHOQUES ALEATÓRIOS}

Em grande parte dos modelos da nova síntese neoclássica, os ciclos de negócios são originados por choques tecnológicos, monetários ou fiscais. Seguindo essa linha, foi examinado um modelo com choques múltiplos relacionados a alterações na produtividade e no estoque monetário (oferta nominal de moeda). Para o choque tecnológico, foi considerado o parâmetro $z$, definido a partir de processo autorregressivo de primeira ordem originado da função de produção apresentada em (2) e reproduzida em (15), tal que:

$$
z_{t}=\rho z_{t-1}+\varepsilon_{t}, \operatorname{com} 0<\rho<1
$$

sendo $\rho$ o parâmetro de persistência do choque e assume-se que $\varepsilon_{t}$ é serialmente não correlacionado com média zero. Conceitualmente, o choque tecnológico é obtido por meio da estimação do resíduo de Solow $(z)$, que corresponde à parcela do produto agregado que não é explicada nem pelo capital e nem pelo trabalho.

A especificação do processo estocástico para o estoque nominal de moeda foi determinada a partir da definição da taxa de crescimento médio de longo prazo da oferta nominal de moeda, denotado por $\Theta^{S S}$. Para tanto, assume-se que $u_{t}=\Theta_{t}-\Theta^{S S}$ é consistente com o desvio no período $t$ da taxa de crescimento de seu valor médio de equilíbrio no estado estacionário. Assim sendo, $u_{t}$ é considerado como o processo estocástico:

$$
u_{t}=\gamma u_{t-1}+\xi_{t}, 0 \leq \gamma<1
$$

em que $\xi_{t}$ é o termo de erro, não correlacionado e $\gamma$ o parâmetro de persistência do processo estocástico. Econometricamente, o choque monetário foi calibrado pela estimação do processo autorregressivo de primeira ordem para, $M$, no conceito $M 2^{1}$, por

\footnotetext{
1 No modelo MIU original, os saldos monetários reais são obtidos a partir da oferta nominal de moeda no
} conceito M1. Entretanto, na economia brasileira, os ativos que oferecem certa proteção contra o processo 
meio da estimação do desvio-padrão de $u_{t}$ obtido a partir de $M_{t}=\gamma M_{t-1}+(1-\gamma) \Theta+u_{t}$, conforme proposto por Cooley e Hansen (1995).

Faz-se importante discutir que o choque monetário atrela-se teoricamente ao instrumento de política monetária utilizado como variável exógena ao sistema. Sobre isso, embora desde meados de 1999 a política monetária tenha sido guiadapelo regime de metas de inflação, tendo a taxa de juros como instrumento da referida política (ver VASCONCELOS e DIVINO, 2012), a economia brasileira alternou distintos regimes no período pós-Real. No regime de metas, a autoridade monetária - Banco Central - determina a taxa de juros, ao passo que a oferta e a demanda de moeda se ajustam endogenamente àquela taxadeterminadapara atingir o novo equilíbrio. Logo, a oferta de moeda deixa de ser instrumento de política, ainda que indiretamente ela sofra alterações devido a mudanças na taxa de juros.

Para tanto, o choque monetário definido pelo estoque nominal de moeda, conquanto esteja em vigência o regime de metas de inflação, ao mesmo tempo em que não elimina os efeitos sobre as variáveis reais e nominais, sendo eles determinados de forma indireta, possibilita discutir comparativamente os resultados da dinâmica cíclica da economia brasileira obtidos a partir de choques na taxa de juros.

\section{RESULTADOS}

\subsection{CALIBRAÇÃO E VALORES DOS PARÂMETROS}

A calibração dos parâmetros constantes nas equações dos modelos e que caracterizam o comportamento no estado estacionário estão expostas na Tabela 1. A partir dos respectivos parâmetros foram realizadas as simulações da economia artificial e das economias padrão e monetárias. Para caracterizar o comportamento cíclico das diferentes variáveis foram utilizadas duas transformações.Primeiramente, foi obtido o logaritmo das séries e, em seguida, removida a tendência suavizada usando o filtro de Hodrick-Prescott com parâmetro de suavização de 1600, padrão para dados trimestrais, similar ao procedimento realizado por Kanczuk (2004).

No processo de calibração, os parâmetros $\alpha, \delta, \beta$ e $\Theta$ foram obtidos a partir dos dados da economia brasileira, com base nas séries macroeconômicas, já os demais $(a, b$,

inflacionário são os depósitos de curto prazo, aplicações financeiras - poupança -, títulos emitidos por instituições depositárias, entre outros ativos, de forma que a oferta de moeda no conceito M2 representa melhor os saldos monetários reais no contexto da economia analisada. Discussão encontra respaldo em Cerqueira (2007), que enfatiza que no período pós-Real, o agregado monetário relevante passa a ser o M2, sobremaneira, pelo fato de os títulos públicos serem substitutos da moeda. 
$\eta, \Phi, \rho, \gamma, \sigma_{\varepsilon}$ e $\left.\sigma_{\varnothing}\right)$ foram obtidos a partir de estimações econométricas e expressões calculadas pelo modelo matemático. Ressalta-se que, para ambas as simulações, MIU e CIA, são utilizados os mesmos parâmetros. Ademais, todas as estimativas e parâmetros foram obtidos com base em dados trimestrais para o período correspondente ao terceiro trimestre de 1994 ao quarto trimestre de 2013.

Tabela 1 - Parâmetros utilizados nas simulações dos modelos MIU e CIA

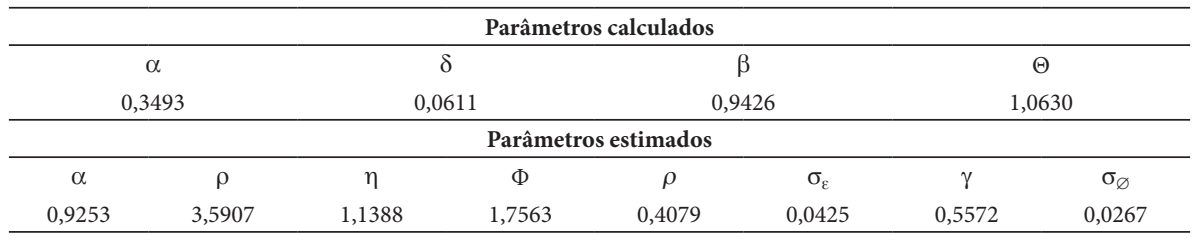

Fonte: Elaboração dos autores. Resultados das simulações.

À participação do capital na renda nacional obteve-se 0,3493, calculado a partir da razão entre o Excedente Operacional Bruto (EOB) e o PIB. Ressalta-se que foi considerado EOB descontado da remuneração dos autônomos. A taxa de depreciação foi estimada em $6,11 \%$, obtida a partir da equação de Euler para o steady state da lei de movimento do capital, dividindo-se a parcela do investimento-produto pela razão capital-produto $\left(i^{S S} / y^{S S}\right)=\delta\left(k^{S S} / y^{S S}\right)$. Para o cálculo foi considerada a razão média $i^{S S}$ $/ y^{S S}$ de $17,49 \%$ e a razão média $k^{S S} / y^{S S}$ de 2,86 . A partir do cálculo de $\alpha$ e $\delta$ foi possível obter a taxa de desconto intertemporal, para a qual se encontrou 0,9426 , valor que sinaliza que os agentes valorizam mais o consumo presente e menos o futuro.

O último dos parâmetros obtido diretamente dos dados da economia brasileira corresponde à taxa de crescimento monetário, para a qual se obteve 1,0629. Parâmetro que foi calibrado a partir do crescimento de 6,2958\% da oferta nominal de moeda, no conceito M2, e das condições consistentes com o estado estacionário, $\Theta=1+\theta^{S S}$.

Para a estimação dos parâmetros referentes à elasticidade consumo da demanda de moeda, $a$, e o inverso da elasticidade juros da demanda monetária, $b$, seguiu-se a formulação utilizada por Goldfeld e Sichel (1990) e Chari et al. (1990), como segue $\log \frac{M_{t}}{P_{t} N_{t}}=\frac{1}{b} \log \left(\frac{1-a}{a}\right)+\log C_{t}-\frac{1}{b} \log \left(\frac{j}{1-j}\right)+\mu_{t}$

. Nesta especificação, o $\log$ da demanda real de moeda é uma função positiva do $\log$ do consumo agregado e uma função negativa do $\log$ da taxa nominal de juros. O termo de erro é não correlacionado, tem média zero e variância $\sigma_{\mu}^{2}$. Quantitativamente, obteve-se $a=0,9253$ e $b=3,5907$, sendo $b$ consistente com uma elasticidade juros da demanda de moeda de $-0,27$. As informações completas sobre estimativas e os testes de diagnóstico estão apresentados no Anexo A. 
O inverso da elasticidade da oferta de trabalho, $\eta$, foi obtido a partir da estimação da função de oferta do trabalho. Para a qual, considerou-se que a quantidade de trabalho ofertado é função do salário real e da taxa real de juros, conforme proposto pela teoria dos ciclos reais de negócio (ver SNOWDON e VANE, 2005). A estimativa encontrada àelasticidade da oferta de trabalho foi de 0,8781 , o que implica um valor para $\eta$ de 1,1388 . As estimações detalhadas, como também os testes realizados podem ser consultados no Anexo B.

No que tange ao parâmetro indicativo do inverso da elasticidade de substituição intertemporal no consumo, $\Phi$, considerou-se que o agente representativo aloca, no estado estacionário, um terço do tempo disponível (oito horas diárias) ao mercado de trabalho, tal que $h^{s S}=1 / 3$. Utilizando a estimativa de $\eta$ e a indivisibilidade do trabalho e aplicando a expressão $\left[\eta h^{S S} /\left(1-h^{S S}\right)\right]^{-1}$ obteve-se $\Phi=1,7563$.

Os seguintes parâmetros relacionam-se à persistência da produtividade, $\rho$, e ao choque de produtividade, $\sigma_{\varepsilon}$, os quais foram obtidos a partir da estimação do resíduo de Solow, $z$. Em relação ao primeiro, obteve-se 0,4079 , calibrado a partir do processo autorregressivo de primeira ordem da produtividade total dos fatores e 0,0425 (ou $4,25 \%)$ para o choque tecnológico, medido pelo desvio-padrão filtrado do processo autorregressivo. As estimativas completas, incluindo o processo autorregressivo e os testes encontram-se no Anexo C.

Cabe mencionar que, para ambos os parâmetros $\left(\rho\right.$ e $\left.\sigma_{\varepsilon}\right)$ não se encontra consenso na economia brasileira, haja vista que as séries referentes à participação do capital e do trabalho na renda, necessárias à obtenção dos resíduos, não são calculadas e disponibilizadas em bases oficiais, sendo assim construídas a partir de diversas medidas e proxies. Logo, encontra-se certa variabilidade nos resultados desses parâmetros (ver ELLERY JR., GOMES e SACHSIDA, 2002; KANCZUK, 2002, 2004; e BENDER FILHO et al., 2012). Dadas essas dificuldades, em determinadas situações, os referidos parâmetros são ajustados de forma a reproduzir a volatilidade dos ciclos reais de negócios.

Os dois últimos parâmetros correspondem ao coeficiente de persistência do crescimento monetário, $\gamma$, e ao choque monetário, $\sigma_{\varphi}$, os quais foram obtidos a partir da estimação do processo autorregressivo de primeira ordem para o crescimento do estoque nominal de moeda. A partir da calibração do modelo autorregressivo (ver Anexo D - Tabela D.1), à persistência do crescimento monetário obteve-se 0,5572 e para o choque monetário, obtido pelo desvio-padrão filtrado do resíduo da regressão do crescimento monetário, 0,0267 (ou 2,67\%). 


\subsection{ECONOMIA ARTIFICIAL}

À obtenção das economias padrão considerou-se que as propriedades cíclicas2 são determinadas pela inclusão de choques tecnológicos positivos e crescimento monetário constante, de acordo com a teoria dos ciclos reais. Além disso, buscando avaliar o efeito do crescimento monetário sobre a oferta de trabalho e o consumo no estado estacionário, foi considerado que a elasticidade da oferta de trabalho com relação à taxa de crescimento da oferta nominal de moeda depende da relação entre o inverso da elasticidade juros da demanda de moeda e o inverso da elasticidade de substituição intertemporal do consumo, $(b-\Phi)$, para as quais se encontrou relação positiva.

Essa relação indica que a utilidade marginal do consumo é decrescente com a moeda e o consumo, apresentando assim complementaridade. Com isso, a inflação torna-se um canal à geração de efeitos reais sobre os ciclos de negócios. Situação em que os agentes tendem a ser mais sensíveis a mudanças na demanda de moeda do que no padrão de consumo em resposta a alterações na taxa nominal de juros, o que determina um baixo grau de aversão ao risco, com o efeito substituição prevalecendo (ver BENDER FILHO et al., 2012).

A partir de tais parâmetros, foram simuladas as economias denominadas padrão, cujos resultados se encontram na Figura 1 e Anexo E - Tabela E.1. Do lado real da economia, ao analisar o produto agregado, em ambos os modelos, verificou-se que a volatilidade foi levemente superior à encontrada na economia real (2.2615), contudo no modelo MIU o desvio-padrão do ciclo foi cerca de $7 \%$ superior, enquanto que no modelo CIA a diferença foi menor, de cerca de 3\%. Tais resultados permitem verificar que os modelos simulados reproduziram de forma satisfatória as propriedades cíclicas da economia brasileira no período pós-estabilização.

Quando analisado o consumo agregado, observa-se que a volatilidade encontrada nas economias artificiais foi inferior àquela obtida na economia real, de 2.0060, resultado consistente com os fatos estilizados discutidos por Cooley e Prescott (1995) e Cooley e Hansen (1995), sendo que os modelos MIU e CIA reproduziram cerca de $56 \%$ e $75 \%$ do desvio-padrão do ciclo, respectivamente. Ademais, evidencia-se o comportamento fortemente pro-cíclico do consumo em ambas às economias padrão, com a correlação simulada pelo modelo MIU mais consistente com os fatos estilizados, enquanto que no modelo com rigidez nominal, a correlação foi superestimada, indicando maior associação com o ciclo econômico. 2 Foram utilizadas técnicas computacionais à aproximação na forma log-linear (ver UHLIG, 1999; WALSH
2003). 
Todavia, convém destacar que o comportamento similar entre as propriedades cíclicas do produto e do consumo agregado consiste em um dos fatos estilizados dos ciclos de negócios, por considerar que no longo prazo ambos os agregados tendem a apresentar trajetória comum, consistente com a hipótese da renda permanente.

Já o investimento agregado apresentou comportamento duas vezes mais volátil que o produto agregado na economia real (6.0166), dinâmica também encontrada nas economias padrão. Porém, no modelo MIU, a volatilidade foi marginalmente superior à encontrada na economia brasileira, enquanto que no modelo CIA foi levemente inferior. $\mathrm{Na}$ análise das correlações, em ambas as economias simuladas, os comovimentos $(0,97$ e 0,94$)$ foram mais próximos ao longo do ciclo econômico quando comparados com a relação obtida à economia real $(0,74)$.

\section{Figura 1 - Benchmark economy e economias artificiais com choque tecnológico e crescimento monetário constante, no período entre 1994 e 2013}
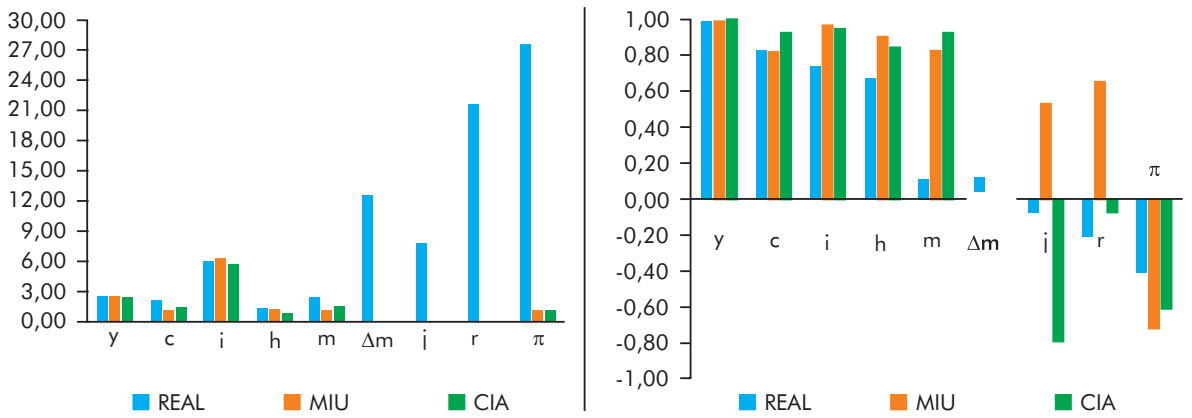

Fonte: Elaboração do autor. Resultados das simulações.

Complementando o conjunto de variáveis reais, verifica-se que os desvios-padrão do ciclo das horas trabalhadas diferenciaram-se nas economias simuladas, sendo que no modelo MIU a volatilidade de $h$ foi de aproximadamente $90 \%$ daquela encontrada nos dados da economia brasileira (1.1955), enquanto que no modelo CIA a volatilidade correspondeu a 60\%. Às correlações contemporâneas, observou-se que as economias padrão superestimaram as relações ao longo do ciclo econômico (0.9026 e 0.8425 para os modelos MIU e CIA).

Diferentemente da economia real, às variáveis nominais, as simulações para ambos os modelos não reproduziramadequadamente o comportamento dinâmico dos ciclos de negócios, exceção foio saldo monetário real, $m$, que apresentou desvio-padrão do ciclo próximo ao da atividade econômica agregada. Já as demais variáveis $\Delta m, j, r$ e $\pi$ caracterizam-se pela elevada volatilidade e movimento contracíclico (movem-se para cima nas contrações e para baixo nas expansões econômicas) com o produto agregado, coerente com os fatos estilizados. 
Como discutido, a variável que apresentou maior aderência à economia real, embora ainda que parcialmente, foi os $m$, cujas economias padrão reproduziram em torno de $46 \%$ e $61 \%$, respectivamente da volatilidade observada nos dados reais. Quanto à direção, ambos os modelos apresentaram movimentos mais próximos do ciclo econômico do que os encontrados à economia real. Além disso, o modelo CIA refletiu melhor ao comportamento contracíclico das variáveis nominais do que o modelo MIU que, para algumas variáveis nominais, caso dos juros reais e nominais, mostrou direção pró-cíclica.

Essa não aderência das variáveis nominais aos fatos estilizados já foi discutida por Backus e Kehoe (1992) e Cooley e Hansen (1995), ao destacarem que características específicas das economias monetárias devem ser incorporadas aos modelos de ciclos de negócios para que estes consigam reproduzir as propriedades das variáveis nominais. Gavin e Kydland (1999) complementaram, quando variáveis nominais são incorporadas aos modelos de ciclos reais de negócios, a estrutura das covariâncias se torna instável, em contraste com a estrutura das séries reais, que tendem a apresentar maior estabilidade.

Comparativamente, esses resultadosparecem não divergir do padrão identificado nas evidências empíricas encontradas à economia brasileira, caso dos estudos de Kanczuk (2004), Cavalcanti e Veredas (2011) e Vasconcelos e Divino (2012), embora estes não tenham explorado analiticamente uma gama maior de variáveis nominais. Assim sendo, quanto a economia real, os achados são compatíveis com grande parte das evidências empíricas acerca dos efeitos de choques, corroborando os fatos estilizados; de outra modo, para as economias monetárias, como as evidências são restritas à economia brasileira, os resultados embora coerentes no que se refere ao comportamento e aos efeitos esperados dos choques, não atenderam a magnitude das volatilidades observadas.

Todavia, conforme discutido por Magalhães (2005), as diferenças obtidas à dinâmica cíclica não invalida os resultados, uma vez que para a economia brasileira, as evidências empíricas mostram que as variáveis calibradas não têm sido razoavelmente aproximadas, suscitando assim a verificação e a adequação de diversos modelos na tentativa de gerar ciclos de negócios plenamente aderentes aos dados reais.

\subsection{ECONOMIAS MONETÁRIAS}

As propriedades cíclicas na presença de choques monetários foram simuladas, para ambos os modelos MIU e CIA, nas denominadas economias monetárias (ver Figura 2 e Anexo E - Tabela E.2). Para isso, foi considerado que o processo de persistência 
do crescimento monetário, $\gamma$, e as mudanças não previstas no crescimento monetário, $\sigma_{\varphi}$ são positivas e não constantes. Estes parâmetros foram obtidos pela estimação do processo autorregressivo de primeira ordem da taxa de crescimento monetário, para a qual se obtiveram 0,5572 e 0,0267 (ou 2,67\%), respectivamente. Os demais parâmetros não foram alterados para ambos os modelos, como também a relação positiva entre $b$ e $\Phi$.

Nas economias monetárias verificaram-se mudanças marginais nas propriedades cíclicas dos agregados reais no modelo MIU, porém no modelo CIA, as alterações foram substanciais, com a volatilidade se elevando para todos os agregados. Alterações que sugerem que a dinâmica cíclica da economia brasileira, em certa medida, responde a algum tipo de rigidez nominal, com destaque para os ciclos das $h$, que nas economias padrão haviam sido subestimadas. Por outro lado, os ciclos do consumo e do investimento apresentaram volatilidade superior àquelas encontradas na economia real.

Quanto à correlação ao longo do ciclo, os comovimentos simulados pelo modelo MIU apresentaram reduzida variação em relação àquelas simuladas na economia padrão, diferentemente do modelo CIA, cujas correlações reproduziram mais adequadamente os fatos estilizados. Em pormenores, o $c$ apresentou comovimentos simulados e efetivos, em ambos os modelos, próximos ao longo do ciclo, o mesmo ocorrendo com as $h$ no modelo CIA. Já o investimento apresentou correlações superiores às efetivas no modelo $\mathrm{MIU}(0,97$ contra 0,74$)$, enquanto que no modelo com restrição de liquidez elas foram inferiores $(0,52$ contra 0,74$)$.

Figura 2 - Economias monetárias com choque tecnológico e com crescimento monetário estocástico, no período entre 1994 e 2013
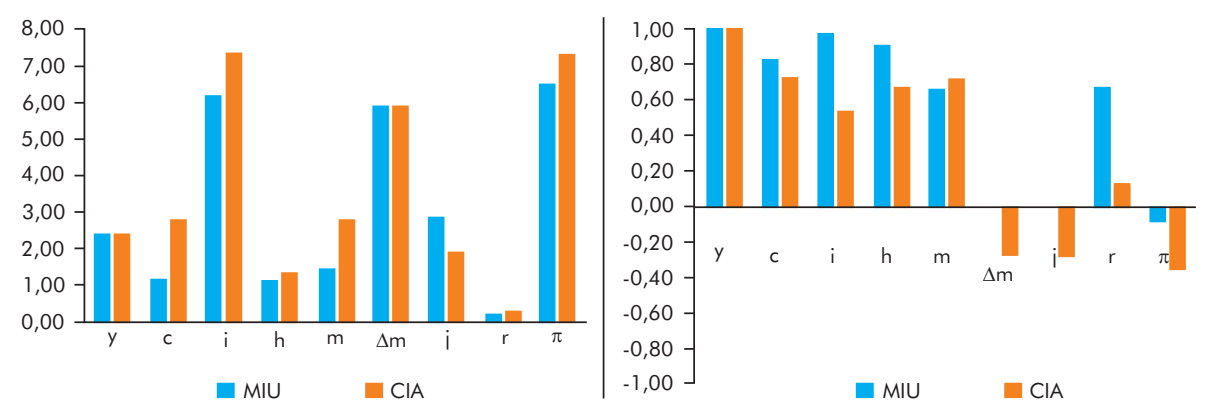

Fonte: Elaboração do autor. Resultados das simulações.

No lado monetário as alterações foram expressivas em ambos os modelos comparativamente às economias padrão, sobremaneira no modelo Cash-in-Advanced, o que possibilitou observar maior adequação aos ciclos de negócios da economia brasileira, 
caso dos ciclos dos saldos monetários reais, que foram reproduzidos quando considerada a persistência e o choque monetário no modelo com rigidez dos preços e salários. Entretanto, a volatilidade do crescimento monetário, embora elevada, foi parcialmente observada.

Da mesma forma, o desvio-padrão do ciclo das variáveis juro nominal e inflação, embora sensivelmente maiores que na economia padrão, nas economias monetárias apenas cerca de $26 \%$ e $23 \%$ e $36 \%$ e $24 \%$ da volatilidade encontrada nos dados reais foi reproduzida. Já o juro real não respondeu a persistência como também ao choque monetário, com as propriedades cíclicas similares àquelas encontradas na economia padrão e, consequentemente, inconsistente com a volatilidade desse agregado na economia brasileira.

Nas correlações contemporâneas, as alterações verificadas em ambas as economias monetárias foram pouco significativas e, de forma geral, mostram tendência de redução do comovimento ao longo do ciclo. Observa-se também que, para praticamente todas as variáveis, o modelo MIU subestimou as correlações enquanto que o modelo CIA as superestimou.

Contudo, embora tenham apresentado ganhos em termos de resultados, as economias monetárias não mostraram aderência satisfatória aos fatos estilizados, quando considerada a correlação entre as séries. Evidências que indicam que os segundos momentos das variáveis nominais parecem não ser robustos a diferentes intervalosde tempo e condições, em consonância com o discutido por Cooley e Hansen (1995) e Gavin e Kydland (1999). Estesresultadostambém encontramdiscussão em Kanczuk (2002), quando destaca que os desvios mais significativos não são facilmente identificados nos períodos de maior instabilidade da economia brasileira, caso dos momentos de planos e crises.

Inclusive, a inserção da persistência e do choque monetário provocou mudança na direção da correlação entre o juro real e o ciclo econômico, de contracíclico para pro-cíclico, sendo esse comportamento mais persistente no modelo MIU. Todavia, esse resultado pode refletir a rigidez dos juros reais frente a contextos econômicos distintos, caso da economia brasileira nas últimas duas décadas, em que os juros reais não respondem em igual proporção e velocidade às mudanças na política macroeconômica.

Esta é uma característica de países como o Brasil, cujo grande devedor líquido é o governo, enquanto o setor privado é credor líquido, condição que determina que expansões nos juros reaistendam a provocar efeitos ambíguos (ver KANCZUK, 2002). Considerando o lazer um bem superior, por um lado, juros reais mais elevados aumentam a riqueza e o efeito-renda indica uma redução na oferta de trabalho; por outro, tornam o trabalho mais atrativo, com o efeito-substituição indicando um aumento na oferta de trabalho. 


\subsection{RESPOSTAS DAS ECONOMIAS MONETÁRIAS A ALTERAÇÕES NO GRAU DE PERSISTÊNCIA DO CRESCIMENTO MONETÁRIO}

Nesta última etapa foram simuladas economias monetárias considerando diferentes níveis de persistência do crescimento monetário, $\gamma$, porém mantendo-se constante os demais parâmetros. Com isso, assume-se que o choque monetário provoca mudanças nos ciclos econômicos quando a taxa de crescimento monetário exibe um processo de persistência, alterando assim as decisões dos agentes econômicos.

A escolha dos níveis de persistência deu-se de forma aleatória, com simulações considerando decis de 0,10 a 0,90 , visto que se tem por objetivo verificar a sensibilidade das propriedades cíclicas da economia brasileira decorrente de mudanças na relação temporal de interdependência do crescimento monetário. Os resultados para ambos os modelos - MIU e CIA - encontram-se nas Figuras de 3 a 6, sendo que nas duas primeiras são expostos os desvios-padrão do ciclo (volatilidades) e nas duas seguintes, o comportamento das correlações contemporâneas. Ademais, as análises são apresentadas seguindo a definição dos agregados econômicos em reais e nominais.

Do lado real, a simulação das economias monetárias com diferentes níveis de persistência não alterou as propriedades cíclicas quando considerado o modelo Money-in-the-Utility. Resultado que decorre do fato de que a tecnologia é mantida inalterada. Diferentemente, no modelo Cash-in-Advanced, as volatilidades mostraram-se sensíveis às variações no grau de persistência do crescimento monetário, porém o comportamento não é comum a todos os agregados reais.

Para o produto agregado e às horas trabalhadas, maiores os níveis de $\gamma$, implicam em dinâmicas mais voláteis, com resposta mais sensível das $h$. Resultado consistente com regimes de política monetária expansionista, cuja prioridade está no alcance de resultados de curto prazo; enquanto que, no longo prazo, o ajuste de preços e salários nominais tende a anular os efeitos desta política. Em linha com as discussões de Tales e Mendonça (2013), quando ressaltam que os choques inesperados de política monetária se destacaram nos períodosde uma política monetária mais conservadora, refletindo-se de forma significativa em uma redução do produto agregado.

Já para o investimento e o consumo agregado, níveis elevados de persistência monetária têm efeito limitado, com a volatilidade se elevando até valores de $\gamma=0,6$ e declinando em níveis superiores. Situação característica de cenários de instabilidade econômica, dado que no horizonte de planejamento, os agentes consideram a incerteza em suas decisões de investimento, conforme discutido em Bender Filho et al. (2012). Porém, à medida que o choque monetário se torna mais persistente, maior tende a ser o período de ajuste da taxa nominal de juros, tornando as decisões de investimento relativamente mais onerosas, o que explica a redução dos desvios positivos do investimento e do consumo em níveis elevados de persistência. 
Figura 3 - Volatilidade da economia monetária - modelo MIU com diferentes níveis de persistência no período entre 1994 e 2013
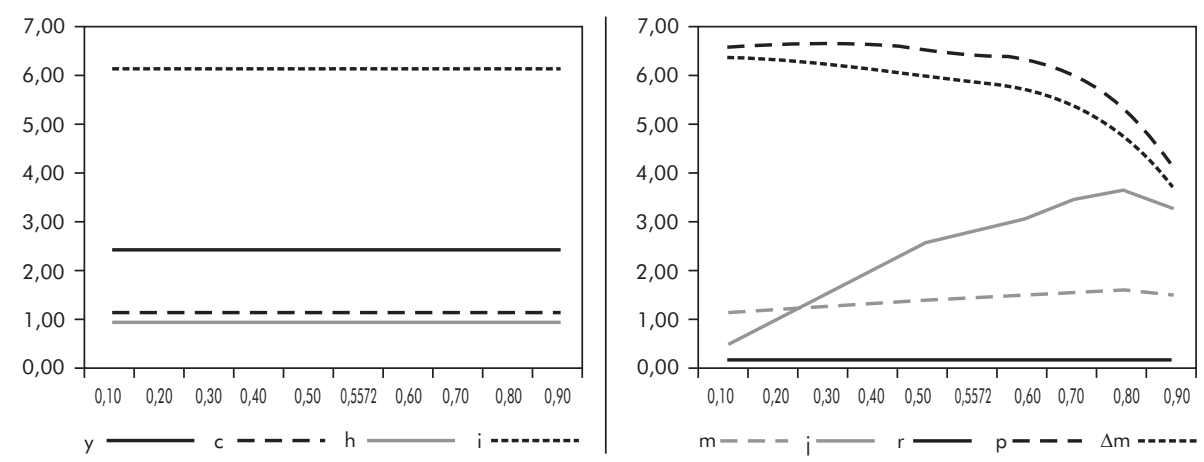

Fonte: Elaboração do autor. Resultados das simulações.

$\mathrm{Na}$ análise das variáveis nominais, mudanças expressivas e dinâmicas mais similares são observadas em ambas as economias monetárias, embora com magnitudes diferenciadas. Todavia, os agregados apresentaram respostas distintas, enquanto que a taxa nominal de juros respondeu positivamente aos choques monetários, com aumento contínuo da volatilidade, a taxa de inflação e a variação dos saldos monetários reais elevaram o desvio padrão do ciclo até o nível de persistência de 0,4 , sendo que $\operatorname{com} \gamma>0,6$, a volatilidade inverteu a tendência e atingiu redução de $40 \%$, para ambos os agregados.

Este comportamento encontra paralelono modelo de política adotado no período pós-estabilização de 1994, cuja variável de ajuste centra-se nos juros nominais, os quais quando elevados controlam o movimento crescente e volátil dos preços (taxa de inflação) ao mesmo tempo em que aumentam o custo de transação, provocando retração na demanda monetária. Resultados na mesma direção daqueles obtidos por Vasconcelos e Divino (2012), justificados pelo fato de os agentes incorporarem em suas expectativaso compromisso da autoridade monetária - Banco Central - com a estabilidade de preços.

Contrapondo, Carvalho (2014) ressaltaque a política implementada a partir do Plano Realgerou condições à consolidação de uma trajetória da taxa de inflação com resistência à queda, rigidez que estaria associada a custos maiores para a desinflação de preços, relação também discutida por Segura-Ubiergo (2012).

A dinâmica das duas outras variáveis, o saldo monetário real e a taxa real de juro, em ambos os modelos, mostrou variações marginais para o processo de persistência do crescimento monetário. A primeira apresentou leve tendência de expansão para níveis crescentes de persistência (entre 0,4 e 0,7), porém com redução da volatilidade para níveis superiores a 0,8 , quando simulado o modelo CIA, enquanto que a segunda praticamente não responde as mudanças na taxa de crescimento da oferta de moeda. $\mathrm{O}$ resultado da dinâmica dos juros reais pode refletir o comportamento paralelo encontrado entre os juros reais e o juro de longo prazo no período pós-Real. 
Figura 4 - Volatilidade da economia monetária - modelo CIA com diferentes níveis de persistência no período entre 1994 e 2013
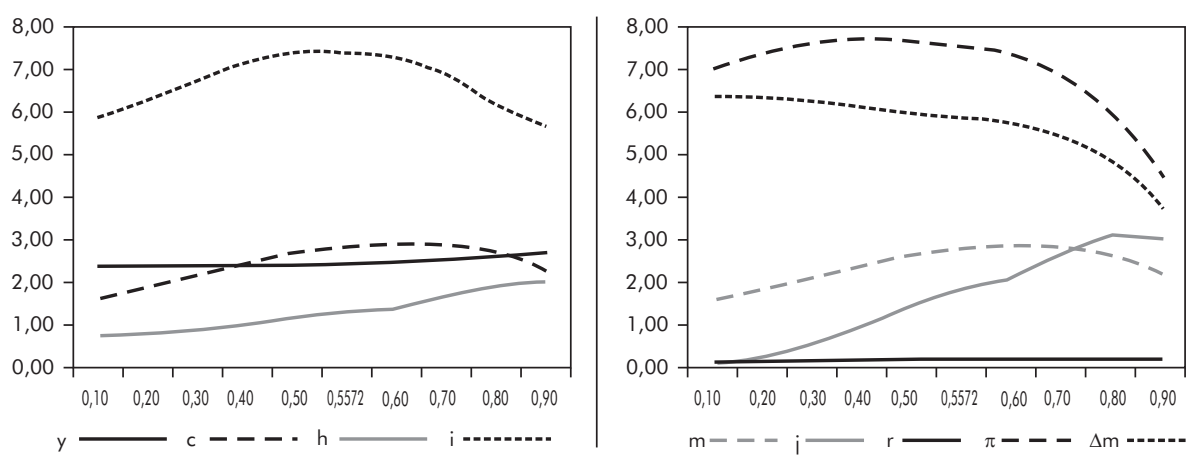

Fonte: Elaboração do autor. Resultados das simulações.

Figura 5 - Correlações da economia monetária - modelo MIU com diferentes níveis de persistência no período entre 1994 e 2013
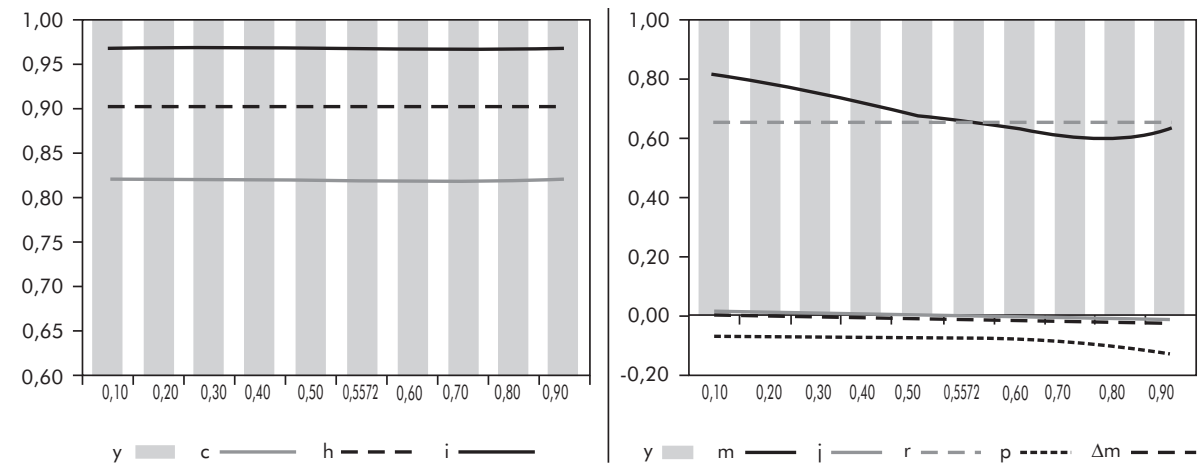

Fonte: Elaboração do autor. Resultados das simulações.

No que tange as correlações contemporâneas, mudanças no nível de persistência do crescimento monetário não alteraram os comovimentos ao longo do ciclo das variáveis reais, quando simulado modelo MIU, sendo o investimento agregado a variável que apresentou maior correlação com o produto, na ordem de 0,96 , enquanto que o consumo a que apresentou menor $(0,83)$. Diferentemente, no modelo CIA as correlações mostraram elevada sensibilidade aos diferentes níveis de persistência.

Este comportamento indica que expansões na taxa de crescimento da oferta de moeda determinam retrações expressivas na correlação das variáveis reais para níveis baixos de persistência, porém esse deslocamento do ciclo econômico ocorreu em níveis e magnitudes diferenciadas. Enquanto que o $c$, variável que apresentou menor sensibilidade, iniciou a fase de recuperação em níveis de persistência superiores a 0,50, 
o $i$, cujo comovimento atingiu queda de $45 \%$, passou a acompanhar o ciclo econômico de forma mais próxima em níveis de persistência superiores a 0,70 , com a correlação praticamente voltando aos níveis iniciais quando a persistência do crescimento monetário atinge níveis superiores a 0,9 .

Sobre esses resultados, tem-se que os choques monetários tendem a incrementar as flutuações do consumo ao mesmo tempo em que reduzem a correlação com o produto agregado, fato que pode ser analisado pelo efeito expressivo sobre o consumo e o investimento agregado, conforme já destacaram Cooley e Hansen (1995). Contudo, ressalta-se que ambas as variáveis ( $c$ e $i$ ), embora com sensibilidade elevada aos diferentes níveis de persistência, mostraram efeitos transitórios, já às $h$ são encontradas evidências de que níveis de persistência crescentes tendem a diminuir a correlação com o ciclo econômico de forma persistente. Com isso, os choques positivos sobre o crescimento monetário induzem a um processo de substituição nas decisões dos agentes em direção a maiores níveis de lazer e menores de oferta de trabalho, como consequência do aumento da taxa de inflação esperada.

\section{Figura 6 - Correlações da economia monetária - modelo CIA com diferentes níveis de persistência no período entre 1994 e 2013}
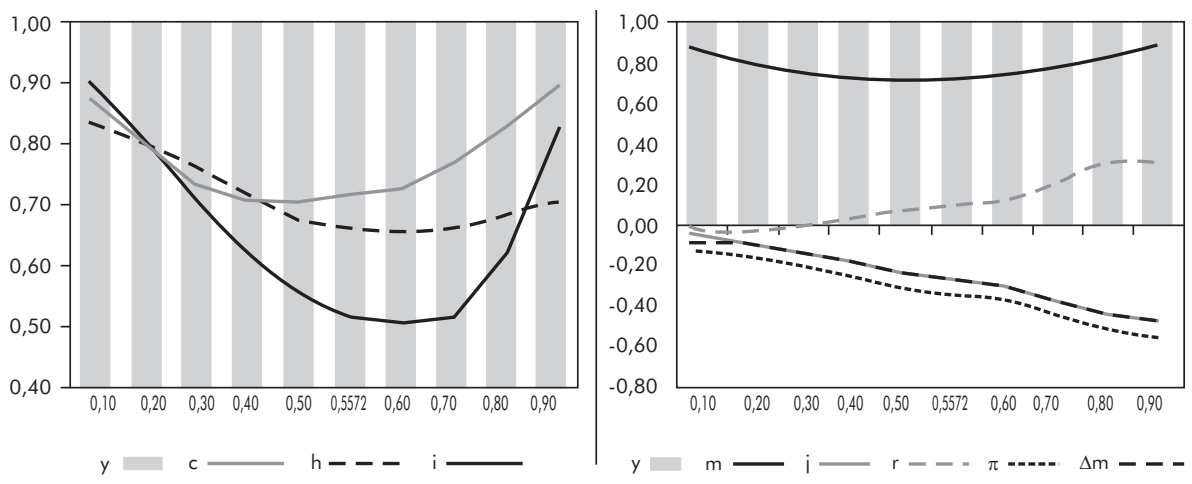

Fonte: Elaboração do autor. Resultados das simulações.

De outro modo, as variáveis nominais apresentaram menor sensibilidade aos diferentes níveis de persistência monetária, em ambos os modelos, sobremaneira no MIU. Nas simulações do modelo CIA, por seu turno, se observou o aumento da correlação dos juros reais com o produto agregado, passando inclusive de contracíclico em níveis baixos de persistência para pro-cíclico para níveis de $\gamma>0,4$.

Para o modelo com rigidez nominal, os resultados sugerem que os movimentos contracíclicos da taxa de inflação, dos juros nominais e da variação do crescimento dos saldos reais de moeda são amplificados quanto maiores forem os níveis de persis- 
tência da oferta de moeda, corroborando as discussões de Kanczuk (2004). A intuição para esse resultado reside no fato de que um maior grau de persistência faz com que os choques monetários se tornem mais importantes na presença de alguma rigidez nominal de preços e salários, dado que os custos de transação se tornam também maiores.

\section{CONCLUSÕES}

Os ciclos de negócios da economia brasileira no pós-estabilização de preçosconstituiu-seno objetivo analítico central, sobremaneira por essa dinâmica ser passível de contrastes. Se, por um lado, a estabilização promoveua redução da incerteza dos agentes econômicos quanto às mudanças não previstas na política monetária; de outro, não permitiu a economiacrescer de formasustentada, reforçando o argumento de que a política macroeconômica centrada em instrumentos monetários pode estar desempenhando papel relevante no comportamento dos agregados reais, confrontando aos argumentos de neutralidade monetária.

Buscando evidências acerca desta discussão, a partir das duas abordagens teóricas (Money-in-the-Utility function e Cash-in-Advanced), foram simuladas economias padrão, com choques reais (produtividade) como fonte preponderante das flutuações cíclicas e, economias monetárias, com a inclusão conjunta de ambos os choques tecnológicos e monetários. Nas economias artificiais padrão observou-se que a magnitude das variáveis reais foi em grande medida reproduzida, enquanto que a dinâmica volátil das variáveis monetárias não encontrou aderência adequada nos modelos simulados. Já nas economias monetárias, a característica observada pela introdução da persistência e do choque monetário, foi à elevação da volatilidade dos ciclos de negócios, sobremaneira no modelo CIA, cujas respostas ocorreram em maior magnitude. Contudo, a inclusão de rigidez nominal permitiu obter-se, de forma mais acurada, a volatilidade dos agregados reais, diferentemente das variáveis nominais, embora também tenham apresentado ciclos mais voláteis, as propriedades dinâmicas não foram totalmente aderentes aos fatos estilizados.

Às economias monetárias com diferentes níveis de persistência, constataram-se resultados distintos para ambos os modelos, enquanto que as propriedades dinâmicas do MIU implicaram em volatilidade dos agregados reais sem contrapartida nos níveis diferenciados de choques monetários, no modelo com rigidez dos preços os agregados reais apresentaram mudanças substanciais, porém com os choques monetários indicando efeitos limitados, dado que para níveis elevados de persistência a volatilidade dos agregados reais declinou, caso do investimento e do consumo agregado. 
No lado nominal, as evidências seguiram padrão similar, com o modelo com rigidez de preços e salários amplificando a volatilidade em níveis baixos de persistência e reduzindo em níveis elevados, corroborando o fato de que a volatilidade da taxa de inflação e da variação dos saldos monetários é acomodada, em níveis de persistência elevados, pelo aumento dos ciclos dos juros nominais, cuja volatilidade apresenta crescimento persistente. Tais resultados acentuam o comportamento contracíclico da inflação e dos juros nominais com produto, situação largamente observada na economia brasileira, visto que em momentos de aceleração inflacionária, tal movimento é controlado políticas de austeridade monetária.

Sumarizando, as economias artificiais mostraram maior aderência aos fatos estilizados da economia brasileira quando considerado o modelo com rigidez dos preços e salários, supondo assim que os ciclos econômicos resultam do comportamento de curto prazo dos agentes econômicos frente às decisões monetárias - definição da quantidade de moeda disponível ou da taxa de juros. Com isso, os efeitos de choques monetários não podem ser subestimados, haja vista que possibilitaram evidenciar comportamentos dinâmicos característicos de economias com certo grau de instabilidade, principalmente, decorrente de processos inflacionários renitentes.

A de se ressaltar que os modelos simulados consideram economias fechadas, o que evidentemente impõe uma limitação aos resultados. Porém, ao suprimir o setor externo, não se está desconsiderando sua importância ainda mais devido ao fato de o Brasil ser um país essencialmente aberto, porém está-se adequando às restrições do modelo. Logo, para outros trabalhos nesta linha, sugere-se a inclusão do setor externo aos modelos simulados.

\section{REFERÊNCIAS}

BACKUS, D. C.; KEHOE, P. International evidence on the historical properties of business cycles. American Economic Review, v. 82, n. 4, p. 864-888, 1992.

BC - BANCO CENTRAL DO BRASIL. Economia e finanças: séries temporais. Brasília: BC, 2014. Disponível em: http://www.bc.gov.br/?SERIETEMP. Acesso em: 02 set. 2014.

BENDER FILHO, R.; VIEIRA, W. C; DIVINO, J. A.; CARVALHO, L. D. Choques monetários e tecnológicos e as flutuações cíclicas na economia brasileira. Economia Aplicada, v. 16, n. 3, p. 501-529, 2012.

CARVAlHO, A. R. A persistência da indexação no Brasil pós-real. Revista de Economia Política, v. 34, n. 2, p. 266-283, 2014.

CAVALCANTI, M. A. F. H.; VEREDAS, L. Propriedades dinâmicas de um modelo DSGE com parametrizações alternativas para o Brasil. Texto para Discussão, IPEA, n. 1588, 2011. 
CERQUEIRA, L. F. Déficit público, indexação, mudanças de regimes e expectativas inflacionárias: a dinâmica da taxa de inflação no Brasil entre 1960 e 2005. Perspectiva Econômica, v. 3, n. 2, p. 82-126, 2007.

CHARI, V. V.; KEHOE, P. J.; McGRATTAN, E. R. Sticky price models of the business cycle: can thecontract multiplier solve the persistence problem? Minneapolis: Federal Reserve Bank of Minneapolis, 1990.

COLLEY, T. F.; HANSEN, G. "Money and the business cycle”. In.: COLLEY, T. F. (Ed.). Frontiers of business cycle research. Princeton: Princeton University Press, 1995.

COLLEY, T. F.; PRESCOTT, E. C. "Economic growth and business cycles”. In.: COLLEY, T. F. (Ed.). Frontiers of business cycle research. Princeton: Princeton University Press, 1995.

CHRSTIANO, L. J.; EICHENBAUM, M.; EVANS, C. L. Nominal rigidities and the dynamic effects of a shock to monetary policy. Journal of Political Economy, v. 113, n. 1 p. 1-45, 2005.

DELFIM NETTO, A. Voto de confiança. Jornal Valor Econômico, Suplemento Novos Rumos da Economia Brasileira, 02/05/2011.

ELLERY JR, R.; GOMES, V.; SACHSIDA, A. Business cycle fluctuations in Brazil. Revista Brasileira de Economia, v. 56, n. 2, p. 269-308, 2002.

FISCHER, S. Long-term contracts, rational expectations and the optimal money supply rule. Journal of Political Economy, v. 85, p. 191-206, 1977.

FRANCIS, N.; RAMEY, V. A. Is the technology-driven real business cycle hypothesis dead? Shocks and aggregate fluctuations revisited. NBER Working Paper Series, n. 8726, 2002.

FRIEDMAN, M.; SCHWARTZ, A. Money and business cycles. The Review of Economics and Statistics, v. 45, n. 1, p. 32-64, 1963.

GAVIN, W. T.; KYDLAND, F. E. Endogenous money supply and the business cycle. Review of Economic Dynamics, v. 2, n. 2, p. 347-367, 1999.

GOLDFELD, S. M.; SICHEL, D. E. “The demand for money”. In: FRIEDMAN, M. B.; HAHN, F. H. Handbook of Monetary Economics.1 ed., v.1, 1990.

GOODFRIEND, M.; KING, R. The new neoclassical synthesis and the role monetary policy. NBER Macroeconomics Annual, 1997.

HANSEN, G. D. Indivisible labor and business cycle. Journal of Monetary Economics, v. 16, n. 3, p. 309-327, 1985.

IBGE - INSTITUTO BRASILEIRO DE GEOGRAFIA E ESTATÍSTICA. Economia. [On-line] IBGE, 2014. Disponível em: <http://www.ibge.gov.br>. Acesso em: 15 jun. 2014.

IPEA - INSTITUTO DE PESQUISA ECONÔMICA APLICADA. Banco de dados. [On-line] IPEA, 2014. Disponível em: <http://www.ipeadata.gov.br>. Acesso em: 10 jul. 2010.

KANCZUK, F. Juros reais e ciclos reais brasileiros. Revista Brasileira de Economia, v. 56, n. 2, p. 249-267, 2002.

KANCZUK, F. Real interest rates and Brazilian business cycles. Review of Economics Dynamics, v. 7, p. 436-455, 2004.

KANCZUK, F.; FARIA JR, F. Ciclos reais para a indústria brasileira? Estudos Econômicos, v. 30, n. 3, p. 335-350, 2000. 
KIYOTAKI, N.A perspective on modern Business Cycle Theory. Economic Quarterly, v. 97, n.3, p. 195-208, 2011.

KYDLAND, F. E.; PRESCOTT, E. C. Time to build and aggregate fluctuations. Econometrica, v. 50, n. 6, p. 1345-1371, 1982.

LONG, J. B.; PLOSSER, C. Real business cycle. Journal of Political Economics, v. 91, n.1, p. 13451370, 1983.

MAGALHÃES, M. Equilíbrio e ciclos. Revista de Economia Contemporânea, v. 9, n.3, p. 509-554, 2005.

MANKIW, G. N. Small Menu Costs and large business cycles: a macroeconomic model of monopoly. The Quarterly Journal of Economics, v. 100, p. 529-539, 1985.

McCANDLESS, G. The ABCs of RBCs: an introduction to dynamic macroeconomic models. Cambridge, MA: Harvard University Press, 2008.

REBELO, S. Real business cycle models: past, present, and future. NBER Working Paper Series, n. 11401, 2005.

SEGURA-UBIERGO, A. The puzzle of Brazil's high interest rates. IMF Working Paper, n. 62, 2012.

SIDRAUSKY, M. Rational choice and patterns of growth in monetary economic. American Economic Review, v. 57, n. 2, p. 534-544, 1967.

SILVEIRA, M. A. C. Using a Bayesian approach to estimate and compare new Keynesian DSGE models for the Brazilian economy: the role for endogenous persistence. Revista Brasileira de Economia, v. 62, n. 3, p. 333-357, 2008.

SIN, H. L.; GAGLIANONE, W. P. Stochastic simulation of a DSGE model for Brazil. Munich Personal Repec Archive, University Library of Munich, n. 20853, 2006.

SNOWDON, B.; VANE, H. R. Modern Macroeconomics: its origins, development and current state. London: Edward Elgar Publishing, 2005.

SOUZA-SOBRINHO, N. F. The role of interest rates in Brazilian business cycles. Working Paper Series, Brasília. n.218, p. 1-43, 2008.

TELES, V. K.; MENDONÇA, D. P. Política monetária em tempos de crise. Revista Brasileira de Economia, v. 67, n. 4, p. 529-548, 2013.

TRIGARI, A. Equilibrium unemployment, job flows and inflation dynamics. European Central Bank, 304, 1-51, 2004.Working Paper Series.

UHLIG, H. A. “Toolkit for analyzing nonlinear dynamic stochastic models easily”. In.: MARIMON, R.; SCOTT, A. (Eds.). Computational methods for the study of dynamic economies. Oxford, UK: Oxford University, 1999.

WALSH, C. E. Monetary theory and policy. 2.ed. Cambridge, MA: MIT, 2003.

WALSH, C. E. Labor market search, sticky prices, and interest rate policies. Review of Economic Dynamics, v. 8, n. 4, p. 829-849, 2005.

VASCONCELOS, B. F. B.; DIVINO, J. A. C. A. O desempenho recente da política monetária sob a ótica da modelagem da DSGE. Texto para Discussão, Brasília, n. 291, p. 1-36, 2012. 
ANEXO A

Tabela A.1 - Resultados do teste de cointegração à demanda de moeda na economia brasileira entre 1994 e 2013

\begin{tabular}{lcccc}
\hline $\begin{array}{l}\text { Hipótese } \\
\text { N. eq. Coint. }\end{array}$ & Eigenvalue & Estatística Traço & Valor crítico 5\% & Prob. \\
\hline None * & 0.343682 & 60.92832 & 42.91525 & 0.0003 \\
At most 1 & 0.201502 & 28.92396 & 25.87211 & 0.0202 \\
At most 2 & 0.144061 & 11.82225 & 12.51798 & 0.0651 \\
\hline
\end{tabular}

Nota: * denota a rejeição da hipótese nula ao nível de 5\%.

Fonte: Elaboração do autor. Resultados das simulações.

Tabela A.2 - Estimativas à demanda de moeda na economia brasileira entre 1994 e 2013

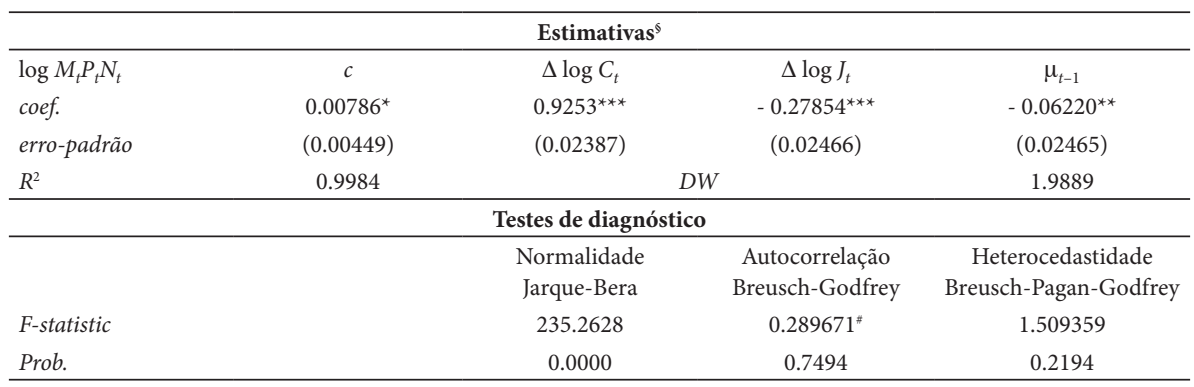

Notas: ${ }^{* * *},{ }^{* *} \mathrm{e} *$ significância estatística a $1 \%, 5 \%$ e $10 \%$, respectivamente.

$\$ M$ corresponde aos meios de pagamento no conceito M2 deflacionado pelo IPCA; $C$ ao consumo final das famílias deflacionado pelo IPCA e $J$ a taxa de juro nominal, definida pela variação da selic. As séries tiveram periodicidade trimestral, com início no terceiro trimestre de 1994 e fim no quarto trimestre de 2013

\# estimado com dois lags.

Fonte: Elaboração do autor. Resultados das simulações.

\section{ANEXOS B}

Tabela B.1 - Resultados do teste de cointegração à oferta de trabalho na economia brasileira entre 1994 e 2013

\begin{tabular}{lcccc}
\hline Hipótese & Eigenvalue & Estatística Traço & Valor crítico 5\% & Prob. \\
\hline N. eq. Coint. & 0.470871 & 64.86282 & 29.79707 & 0.0000 \\
None * & 0.134503 & 16.48709 & 15.49471 & 0.0354 \\
At most $1 *$ & 0.069919 & 5.508761 & 3.841466 & 0.0189 \\
\hline
\end{tabular}

Nota: * denota a rejeição da hipótese nula ao nível de 5\%.

Fonte: Elaboração do autor. Resultados das simulações. 
Tabela B.2 - Estimativas da oferta de trabalho na economia brasileira entre 1994 e 2013

\begin{tabular}{|c|c|c|c|c|}
\hline \multicolumn{5}{|c|}{ Estimativas $^{\S}$} \\
\hline $\log S_{t}$ & $c$ & $\Delta \log w_{t}$ & $\Delta \log r_{t}$ & $\mathrm{v}_{t-1}$ \\
\hline coef. & $-0.0178^{* * *}$ & $0.8781^{* * *}$ & $-0.12617^{\star * *}$ & $-0.3191^{* *}$ \\
\hline erro-padrão & $(0.00521)$ & $(0.04891)$ & $(0.04659)$ & $(0.09864)$ \\
\hline$R^{2}$ & 0.9967 & \multicolumn{2}{|c|}{$D W$} & 1.8502 \\
\hline \multicolumn{5}{|c|}{ Testes de diagnóstico } \\
\hline & & $\begin{array}{l}\text { Normalidade } \\
\text { Jarque-Bera }\end{array}$ & $\begin{array}{l}\text { Autocorrelação } \\
\text { Breusch-Godfrey }\end{array}$ & $\begin{array}{c}\text { Heterocedastidade } \\
\text { Breusch-Pagan-Godfrey }\end{array}$ \\
\hline F-statistic & & 226.6235 & $0.396733^{\#}$ & 2.422445 \\
\hline Prob. & & 0.0000 & 0.6740 & 0.0727 \\
\hline
\end{tabular}

Notas: ***, ** e * significância estatística a 1\%,5\% e 10\%, respectivamente.

$\S 5$ corresponde a quantidade de horas trabalhadas, obtido pela série de horas trabalhadas na indústria dessazonalizada; $w o$ salário real, calculado a partir do rendimento médio do trabalho principal deflacionado pelo IPCA e $r$ a taxa real de juro. As séries tiveram periodicidade trimestral, com início no terceiro trimestre de 1994 e fim no quarto trimestre de 2013.

\# estimado com dois lags.

Fonte: Elaboração do autor. Resultados das simulações.

\section{ANEXOS C}

Tabela C.1 - Persistência e choque tecnológico

\begin{tabular}{|c|c|c|c|}
\hline \multicolumn{4}{|c|}{ Estimativas $^{\S}$} \\
\hline$z_{t}$ & $c$ & $\rho z_{t-1}$ & $\rho z_{t-4}$ \\
\hline coef. & $-0,001531$ & $0,407912^{\star * *}$ & $0,537283^{* * *}$ \\
\hline erro-padrão & $(0,006348)$ & $(0,100571)$ & $(0,082325)$ \\
\hline$R^{2}$ & 66,63 & $D W$ & 1,7601 \\
\hline \multicolumn{4}{|c|}{ Testes de diagnóstico } \\
\hline & $\begin{array}{l}\text { Normalidade } \\
\text { Jarque-Bera }\end{array}$ & $\begin{array}{l}\text { Autocorrelação } \\
\text { Breusch-Godfrey }\end{array}$ & $\begin{array}{c}\text { Heterocedastidade } \\
\text { Breusch-Pagan-Godfrey }\end{array}$ \\
\hline F-statistic & 19,5516 & $2,5820^{\#}$ & 2,3280 \\
\hline Prob. & 0,0001 & 0,1126 & 0,1049 \\
\hline
\end{tabular}

Notas: ***, ** e * significância estatística a $1 \%, 5 \%$ e $10 \%$, respectivamente.

${ }^{\S}$ A série utilizada de $Z$ apresenta periodicidade trimestral correspondente ao período de julho de 1994 a dezembro de 2013.

\# estimado com um lags.

Fonte: Elaboração do autor. Resultados das simulações. 
ANEXOS D

Tabela D.1 - Persistência e choque monetário

\begin{tabular}{|c|c|c|c|}
\hline \multicolumn{4}{|c|}{ Estimativas $^{\S}$} \\
\hline$u_{t}$ & $c$ & $\gamma u_{t-1}$ & $\gamma u_{t-6}$ \\
\hline coef. & $-0,001033$ & $0,557220^{* * *}$ & $-0,154051^{*}$ \\
\hline erro-padrão & $(0,003451)$ & $(0,083791)$ & $(0,083912)$ \\
\hline$R^{2}$ & 35,56 & DW & 1,8067 \\
\hline \multicolumn{4}{|c|}{ Testes de diagnóstico } \\
\hline & $\begin{array}{c}\text { Normalidade } \\
\text { Jarque-Bera }\end{array}$ & $\begin{array}{l}\text { Autocorrelação } \\
\text { Breusch-Godfrey }\end{array}$ & $\begin{array}{c}\text { Heterocedastidade } \\
\text { Breusch-Pagan-Godfrey }\end{array}$ \\
\hline F-statistic & 1,8419 & $0,7502^{\#}$ & 0,2886 \\
\hline Prob. & 0,3982 & 0,4553 & 0,7963 \\
\hline
\end{tabular}

Notas: ***,** e * significância estatística a $1 \%, 5 \%$ e $10 \%$, respectivamente.

${ }^{\S}$ A série utilizada de M2 possui periodicidade trimestral e corresponde ao período entre julho de 1994 e dezembro de 2013.

\# estimado com dois lags.

Fonte: Elaboração do autor. Resultados das simulações.

\section{ANEXO E}

Tabela E.1 - Benchmark economy e economias artificiais com choque tecnológico e crescimento monetário constante, no período entre 1994 e 2013

\begin{tabular}{ccccccc}
\hline \multirow{2}{*}{ Variáveis } & \multicolumn{2}{c}{ Economia Real } & \multicolumn{3}{c}{ MIU } & \multicolumn{2}{c}{ CIA } \\
\cline { 2 - 6 } & DP $[x](\%)$ & CORR $[x, y]$ & DP $[x](\%)$ & CORR $[x, y]$ & DP $[x](\%)$ & CORR $[x, y]$ \\
\hline$y$ & 2.2615 & 1.0000 & 2.4171 & 1.0000 & 2.3160 & 1.0000 \\
$c$ & 2.0060 & 0.8215 & 1.1349 & 0.8219 & 1.5071 & 0.9249 \\
$i$ & 6.0166 & 0.7398 & 6.1367 & 0.9682 & 5.6055 & 0.9440 \\
$h$ & 1.1955 & 0.6752 & 1.0507 & 0.9026 & 0.7069 & 0.8425 \\
$m$ & 2.4404 & 0.1082 & 1.1348 & 0.8207 & 1.5071 & 0.9249 \\
$\Delta m$ & 12.6212 & 0.1138 & 0.0088 & 0.0001 & 0.0096 & 0.0001 \\
$j$ & 7.8209 & -0.0770 & 0.0094 & 0.5299 & 0.0035 & -0.7878 \\
$r$ & 21.7015 & -0.2114 & 0.1789 & 0.6528 & 0.1444 & -0.0645 \\
$\pi$ & 27.7726 & -0.4095 & 0.6046 & -0.7253 & 0.9798 & -0.6107 \\
\hline
\end{tabular}

Fonte: Elaboração do autor. Resultados das simulações.

Tabela E.2 - Economias monetárias com choque tecnológico e com crescimento monetário estocástico, no período entre 1994 e 2013

\begin{tabular}{|c|c|c|c|c|}
\hline \multirow{2}{*}{ Variáveis } & \multicolumn{2}{|c|}{ MIU } & \multicolumn{2}{|c|}{ CIA } \\
\hline & $\mathrm{DP}[x](\%)$ & $\operatorname{CORR}[x, y]$ & $\mathrm{DP}[x](\%)$ & $\operatorname{CORR}[x, y]$ \\
\hline$y$ & 2.4172 & 1.0000 & 2.4112 & 1.0000 \\
\hline$c$ & 1.1402 & 0.8189 & 2.7703 & 0.7167 \\
\hline$i$ & 6.1394 & 0.9674 & 7.2940 & 0.5189 \\
\hline$h$ & 1.0513 & 0.9024 & 1.2675 & 0.6622 \\
\hline$m$ & 1.4495 & 0.6482 & 2.7703 & 0.7167 \\
\hline$\Delta m$ & 5.8521 & -0.0088 & 5.8521 & -0.2725 \\
\hline$j$ & 2.8490 & -0.0072 & 1.8588 & -0.2744 \\
\hline$r$ & 0.1790 & 0.6527 & 0.2179 & 0.0956 \\
\hline$\pi$ & 6.4446 & -0.0771 & 7.2940 & -0.3438 \\
\hline
\end{tabular}

Fonte: Elaboração do autor. Resultados das simulações. 